\title{
SAÚDE E FELICIDADE EM TEMPOS DE PANDEMIA: É POSSÍVEL?
}

\author{
HEALTH AND HAPPINESS IN TIMES OF PANDEMIC: IS IT POSSIBLE?
}

Katia Poles*

\section{RESUMO}

Há mais de um ano vivemos, cotidianamente, imersos em um contexto de medo, dúvidas, incertezas e angústias em função da pandemia de Covid-19, iniciada oficialmente no Brasil em março de 2020. Vimos nossa vida ser virada de cabeça para baixo: perdemos nosso locus habitual no mundo - trabalho, escola, comunidade etc. - e passamos a ocupar, quase exclusivamente, o ambiente doméstico, devido às medidas de distanciamento e/ou isolamento social. Todas essas situações provocaram e provocam impactos significativos em nossa vida, face às novas demandas que nos foram apresentadas. Diante desse cenário fecundo e propício ao adoecimento físico e mental, considerados aqui de maneira indivisível, parece-nos ainda mais quimérico pensar em felicidade. Seria possível, então, viver saudável e feliz diante de tantos infortúnios? Assim, o presente texto tem como objetivo discutir as possibilidades para a construção de saúde e felicidade em tempos de pandemia. Embora construir saúde e felicidade em meio a tantas adversidades que a pandemia nos impõe seja, aparentemente, algo extremamente complexo, faz-se necessário e urgente refletir sobre as várias formas reais e possíveis para uma vida mais harmoniosa e equilibrada.

PALAVRAS-CHAVE: saúde; felicidade; bem-estar subjetivo, psicologia positiva; pandemia.

\section{ABSTRACT}

For more than a year, we have been living on a daily basis, immersed in a context of fear, doubts, uncertainties and anguish due to the Covid-19 pandemic, which officially started in Brazil in March 2020. We have seen our lives turned upside down: we lost our usual locus in the world - work, school, community etc. - and we started to occupy, almost exclusively, the domestic environment, due to the measures of distancing and/or social isolation. All these situations provoked and provoke significant impacts in our life, given the new demands that were presented to us. Faced with this fertile scenario, conducive to physical and mental illness, considered here in an indivisible way, it seems to us even more chimerical to think about happiness. Would it be possible, then, to live healthy and happy in the face of so many misfortunes? Thus, this manuscript aims to discuss the possibilities for building health and happiness in times of pandemic. Although building health and happiness amidst so many adversities that the pandemic imposes on us is, apparently, something extremely complex, it is necessary and urgent to reflect on the various real and possible ways for a more harmonious and balanced life.

KEYWORDS: heath; happiness; subjective well-being; positive psychology; pandemic.

\footnotetext{
* Mestre e Doutora em Enfermagem (USP), Enfermeira (UNESP), Especialista em Pediatria e Terapia de Família (UNIFESP). Professora Adjunta III do Curso de Medicina da UFLA. E-mail: katia.poles@ufla.br.
} 


\section{INTRODUÇÃO}

Há mais de um ano vivemos, cotidianamente, imersos em um contexto de medo, dúvidas, incertezas e angústias em função da pandemia de Covid-19, iniciada oficialmente no Brasil em março de 2020. Em dezembro de 2019, a Organização Mundial da Saúde (OMS) foi alertada sobre vários casos de pneumonia na cidade de Wuhan, província de Hubei, na China. Tratava-se de uma nova cepa ou tipo de coronavírus, que não havia sido identificada antes em seres humanos. Na sequência, em janeiro de 2020, a OMS declarou que o surto do novo coronavírus constituía uma emergência de saúde pública de importância internacional — o mais alto nível de alerta da Organização. No mês seguinte (fevereiro de 2020), foi confirmado o primeiro caso de coronavírus no Brasil (ORAGANIZÇÃO PAN-AMERICANA DE SAÚDE, [202-]). Os principais eventos relacionados à pandemia de Covid-19 são pontuados na figura a seguir:

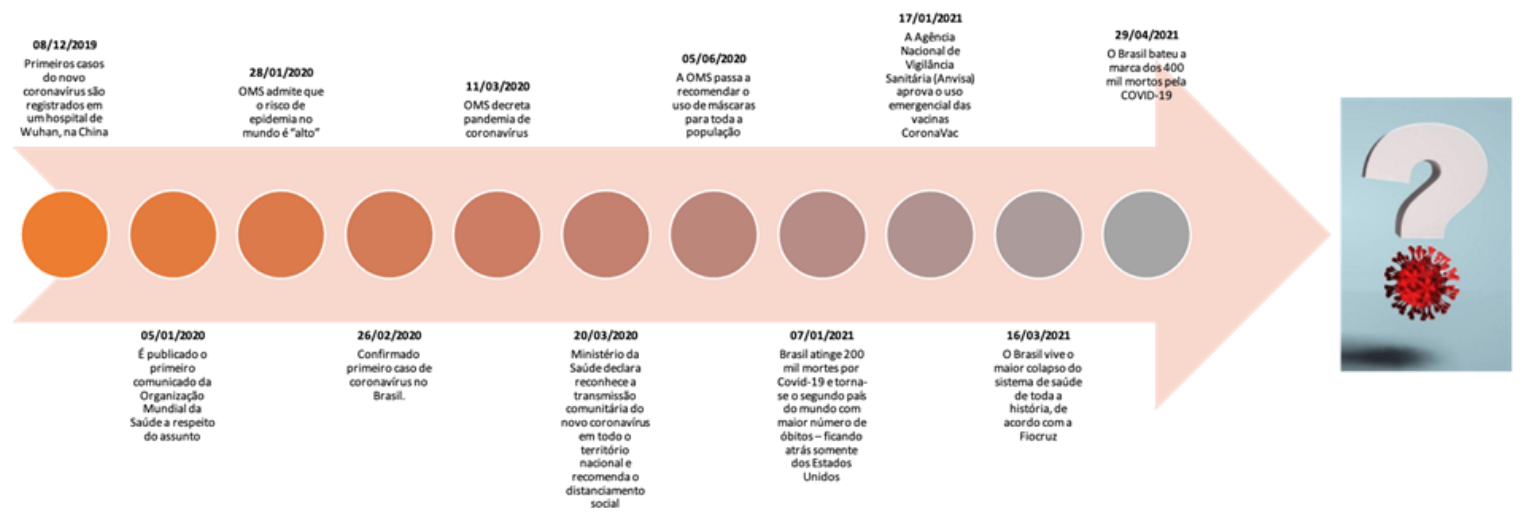

Figura 1: Linha do tempo da pandemia de Covid-19 no Brasil e no mundo

Nesse cenário, inicialmente falávamos sobre um "novo normal", ou seja, uma nova forma de organizar a vida, que, dia após dia, foi se transformando em nossa realidade de vida possível diante de um cenário de mudanças drásticas na forma de ser, pensar e agir. O que imaginávamos que teria um prazo de validade curto para solução tornou-se uma circunstância que se arrasta há mais de um ano e, ainda, sem previsão de desfecho ou finalização. O tal "novo normal" já está ultrapassado, superado e ressignificado.

Vimos nossa vida ser virada de cabeça para baixo: perdemos nosso locus habitual no mundo - trabalho, escola, comunidade etc. - e passamos a ocupar, quase exclusivamente, o 
ambiente doméstico, devido às medidas de distanciamento e/ou isolamento social. Todas essas situações provocaram e provocam impactos significativos em nossa vida, face às novas demandas que nos foram apresentadas. Considerando que nós, humanos, somos seres sociais — é na interação com o mundo que crescemos, amadurecemos e nos transformamos —, viver de forma restrita quanto às possibilidades de relações interpessoais nos tem acarretado uma série de problemas, tanto na dimensão física quanto mental.

Diante desse cenário fecundo e propício ao adoecimento físico e mental, considerados aqui de maneira indivisível, pois a saúde física interfere na saúde mental e vice-versa, parecenos ainda mais quimérico pensar em felicidade. Seria possível, então, viver saudável e feliz diante de tantos infortúnios?

Desse modo, o presente artigo tem como objetivo discutir as possibilidades para a construção de saúde e felicidade em tempos de pandemia.

\section{SOBRE A SAÚDE}

De acordo com a OMS, podemos entender saúde como um equilíbrio nas dimensões físicas, emocionais, sociais e, mais recentemente, também espirituais, ou seja, nos mantermos saudáveis vem-se tornando um desafio e uma construção diária, em meio a tantas adversidades impostas pela pandemia. Além da escassez de contato pessoal - ao vivo e em cores, que confere qualidade às nossas relações — também vivemos em constante estresse, em função de os limites entre vida pessoal e profissional se mostrarem imprecisos e borrados, às novas demandas de uma vida em constante ameaça, às dificuldades financeiras, às variadas perdas tanto materiais como emocionais, como também em virtude de mudanças em nossos hábitos de sono, alimentação, atividade física, lazer, entre outros.

No geral, só tomamos consciência da nossa saúde quando deixamos de desfrutar dela, então, pode ser muito complicado reverter o prejuízo. Lembre-se: ter e manter saúde é algo trabalhoso, exige esforço e dedicação, como outros objetivos de melhorias de vida.

Ao considerarmos os fatores elencados, além daqueles próprios da experiência de cada um, infere-se que a saúde, entendida aqui na amplitude da sua concepção, encontra-se constantemente ameaçada, não só em função dos riscos de uma possível contaminação e adoecimento, como também dos vários fatores vividos nos âmbitos emocional, social e espiritual. Além desses, ressalta-se o fator econômico, que assola muitas pessoas no contexto da pandemia e interfere diretamente na saúde como um todo. 
Por outro lado, talvez este seja um momento propício para repensarmos a forma como cuidamos do nosso corpo, mente e espírito e construímos saúde. Somos convidados - quase convocados - a olhar para o nosso interior e refletirmos sobre a real importância que atribuímos ao nosso cuidado, entendido aqui como autocuidado.

Quantas e quantas vezes negligenciamos a nós mesmos para atender demandas externas, seja no âmbito familiar ou no profissional? Muitas vezes largamos absolutamente tudo que estamos fazendo para "apagar incêndios" ou, ainda, para atender às necessidades de alguém. Não há o menor problema em fazer isso em determinados momentos ou situações; por exemplo, se uma criança se machuca, é natural largarmos tudo para socorrê-la, mas tornar esse um modus operandi é altamente prejudicial.

Então, convido-o a colocar o foco em si e (re)pensar sobre o que tem feito para se cuidar, com todo amor e generosidade que costuma oferecer aos outros. Autocuidado pode ser entendido como a prática de atividades iniciadas e executadas pelos indivíduos em benefício próprio para a manutenção da vida e do bem-estar.

Sempre que penso sobre autocuidado, gosto de utilizar a Teoria das Necessidades Humanas, proposta pelo psicólogo norte-americano Abraham Maslow, na década de 1950, para entender as nossas necessidades (MASLOW, 1978). Embora não seja uma teoria recente, ela ainda é largamente utilizada para refletirmos a respeito do autocuidado. Maslow propõe uma hierarquia de necessidades a serem satisfeitas por qualquer ser humano que pretenda se realizar, conforme apresentado na Figura 2.

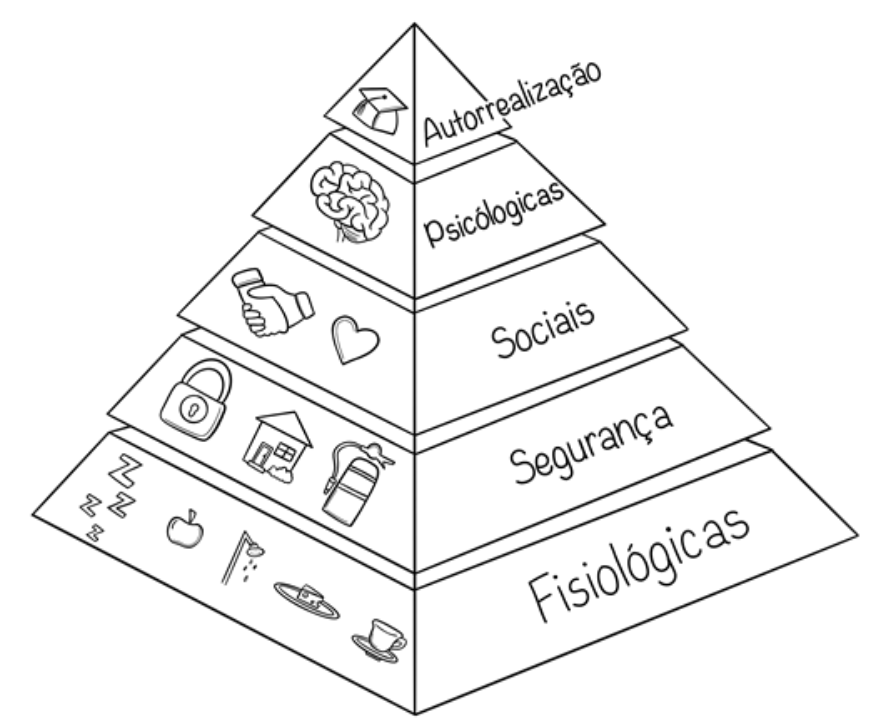

Figura 2: Pirâmide das Necessidade Humanas Básicas de Abraham Maslow 
Na base da pirâmide estão as necessidades fisiológicas, isto é, as necessidades mais elementares para a manutenção de qualquer pessoa, tais como alimentação, hidratação, excreção e sono. Quem nunca negligenciou uma necessidade dessa ao comer mal, não se hidratar o suficiente ou suprimir horas de sono? Muitas vezes, ao fazermos isso, acreditamos que "ganharemos tempo" e seremos mais eficientes na execução de uma determinada tarefa. Entretanto, não nos damos conta de que esse é o nível mais básico de necessidades a serem satisfeitas e, de acordo com Maslow, é impossível ascender para outros níveis da pirâmide quando não atendemos tais necessidades.

Pensando na questão da nutrição, da hidratação e das práticas de atividades físicas, tomarei como base as orientações propostas pelo Ministério da Saúde, que podem ser encontradas nos diferentes guias e diretrizes desse Órgão. Minha intenção aqui é sensibilizá-lo para coisas simples e importantes. Imagino que a maioria das pessoas sabe disso, mas, ainda assim, tem muita dificuldade para colocar em prática. Desse modo, fica o convite para que você reflita e reveja as seguintes recomendações:

- Faça pelo menos três refeições (café da manhã, almoço e jantar) e dois lanches saudáveis por dia. Não pule as refeições.

- Dê preferência aos alimentos in natura ou minimamente processados ao invés dos processados ou ultraprocessados.

- Dê preferência aos alimentos com menores quantidades de gorduras, em especial de gorduras trans.

- Evite excesso de açúcar e alimentos industrializados.

- Diminua a quantidade de sal na comida e retire o saleiro da mesa.

- Beba pelo menos dois litros (seis a oito copos) de água por dia.

- Pratique pelo menos 30 minutos de atividade física 5 vezes na semana, ou 40 minutos de atividades 4 vezes por semana.

Entendo que colocar tudo isso em prática pode soar irreal, mas, pode acreditar: à medida que você se dispõe a dar o primeiro passo e a manter esses hábitos, pouco a pouco serão incorporados na sua rotina, de modo que não haja necessidade de um esforço hercúleo para executá-los.

Com relação ao sono, vale lembrar que é algo extremamente importante para nossa saúde física e mental. O sono desempenha importantes funções: a consolidação da memória e o equilíbrio geral do organismo são as mais importantes. Por isso, cuidar do sono é fundamental para o seu autocuidado. Antes de passar aos próximos níveis, gostaria de ressaltar que seu corpo 
é seu templo, onde você habitará até o fim da existência. Portanto, respeite e cuide dessa dádiva! Especialmente no período de pandemia, faz-se necessário estar ainda mais vigilante quanto aos aspectos relacionados à nossa saúde física, considerando os riscos de adoecimento e também o nosso bem-estar.

Passando ao segundo nível da pirâmide de Maslow, encontraremos as necessidades de segurança. Isso diz respeito à importância de nos sentirmos seguros e protegidos. Nesse nível, encontramos a necessidade de estabilidade, de termos um lar, um emprego, recursos suficientes para mantermos uma vida digna e preservar nossa integridade. Infelizmente, muitas pessoas estão apresentando dificuldades financeiras decorrentes da crise econômica provocada pela pandemia. Então, caso tenhamos o suficiente, não seria oportuno praticar a gratidão por desfrutarmos do que possuímos?

No terceiro nível estão as necessidades sociais, como a necessidade de nos relacionarmos, de dar e receber afeto, de nos sentirmos parte de um grupo e sermos aceitos. Nossa natureza humana nos predispõe a viver em sociedade, não somos uma ilha, isolados do mundo e, como seres sociais, buscamos o convívio com o outro para garantir o nosso bem-estar. Embora seja desafiador suprirmos totalmente as nossas necessidades sociais em função do distanciamento ou isolamento, faz-se necessário valorizarmos as nossas relações íntimas, que desfrutamos diariamente e, na medida do possível, tentar manter o contato com as pessoas queridas, ainda que através dos meios de comunicação digitais. De todo modo, o fundamental é nos sentirmos conectados, mesmo que o distanciamento físico nos imponha limitações quanto ao contato mais próximo e efetivo.

No quarto nível estão as necessidades psicológicas, também conhecidas como de autoestima. As necessidades aqui consistem em se sentir apreciado, ter prestígio e ser reconhecido dentro de um grupo social. Do mesmo modo, também se incluem nesse grupo a autovalorização e o respeito por si. Para suprir tais necessidades, é fundamental o indivíduo se engajar em seu autoconhecimento, a fim de reconhecer o que de fato é importante para si. Viver um momento de restrição quanto às possibilidades de contato com o mundo externo nos convida a fazer um movimento de introspecção e olhar para dentro, para quem eu sou, para o que realmente importa em minha vida, para o sentido da minha existência etc.

E, por fim, no quinto nível, encontramos as necessidades de superação, também chamadas de autorrealização. São as necessidades mais difíceis de alcançar. Nesse nível, o ser humano quer transcender sua própria existência, deixar uma marca, realizar a sua própria obra, 
desenvolver o seu talento ao máximo. São necessidades relacionadas com o desenvolvimento espiritual e com a busca de um sentido maior para a vida.

O autocuidado parece muito complexo, mas, na verdade, é algo simples: basta aprendermos a escutar as necessidades que pulsam dentro de nós e clamam para serem ouvidas. De acordo com Maslow (1978), uma pessoa não pode fazer escolhas sábias na vida a menos que ouse escutar a si mesmo, seu próprio eu, em cada momento da vida. Ao se perguntar "do que eu preciso agora?", pare, pense e sinta, pois a resposta provavelmente está aí dentro de você!

Passemos agora à reflexão sobre a felicidade, algo que nos é tão caro em nossa existência.

\section{SOBRE A FELICIDADE}

Felicidade é um tema atual e, ao mesmo tempo, historicamente muito antigo. O homem é o único animal dotado de capacidade cognitiva para pensar sobre a vida e o seu sentido. Aristóteles, há mais de dois mil anos, apresentou o conceito de Eudaimonia, palavra de origem grega formada a partir dos vocábulos $E u$ (aquilo que é bom) e Daemon (espírito ou alma). Para o filósofo grego cada pessoa possui virtudes e forças, e deve exercê-las buscando a excelência. Nessa perspectiva, a felicidade ocorre quando há o encontro entre pensamento e ação, e a pessoa sente a coerência existencial. Na concepção aristotélica, esse seria o caminho da felicidade. Outros filósofos da Antiguidade ressaltaram, ainda, que é necessário dissociar a felicidade de causas externas e encontrar novas causas, dentro de nós mesmos.

Desde então, tem-se a felicidade como assunto de diversas áreas, como filosofia, sociologia, psicologia, neurociência, entre outras. Pensando especificamente na área da psicologia, disciplina científica nascida no final do século XIX, observa-se que os aspectos negativos ou patológicos do ser humano foram alvo de diversas teorias e pesquisas ao longo de praticamente um século. Porém, foi apenas no final do século XX que teóricos da psicologia humanista, como Abraham Maslow e Carl Rogers, exploraram os aspectos saudáveis ou positivos do ser humano.

Mas foi somente em 2000 que Martin Seligman, então presidente da Associação Americana de Psicologia (APA), fundou a Psicologia Positiva como uma área específica dentro da psicologia. Essa área do conhecimento passou a se dedicar ao estudo e à produção de conhecimentos sobre a felicidade ou bem-estar subjetivo. A Psicologia Positiva surge como 
movimento de investigação dos aspectos potencialmente saudáveis dos seres humanos, em oposição à psicologia tradicional e sua ênfase nos aspectos psicopatológicos. Desde então, temas relacionados à felicidade - como relacionamentos, gratidão, empatia, resiliência, atenção plena, autocuidado - vêm sendo abordados com profundidade pela psicologia. A finalidade é oferecer subsídios para explorar os aspectos positivos que constituem a experiência humana, deixando o enfoque exclusivo na patologia ou no sofrimento em segundo plano. Embora seja uma área relativamente nova no campo científico, hoje é possível encontrar uma vasta literatura para nos ajudar a compreender o que torna o ser humano feliz.

Seligman (2019) propõe o Modelo PERMA — acrônimo formado pelas iniciais das palavras em inglês Positive Emotions (Emoções positivas); Engagement (Engajamento); Relationship (Relacionamentos); Meaning (Sentido); Accomplishment (Realizações) — para explicar o que é a felicidade ou o bem-estar subjetivo.

Vamos enumerar os cinco componentes do Modelo PERMA, fundamentais para alcançar a tão almejada felicidade, e relacioná-los com o contexto atual em que estamos vivendo:

- Emoções positivas: vivenciar mais emoções positivas do que negativas, numa proporção de 3:1. Nós, enquanto seres humanos, temos a tendência de valorizar mais os elementos negativos da nossa experiência, e isso é denominado "viés negativo". Nosso cérebro, ao longo da evolução da espécie, foi sendo treinado ou condicionado a reter ou assimilar com muito mais ênfase as experiências ou as emoções negativas do que as positivas, visando à manutenção do gênero humano (KAFFENBERGER et al., 2010). Possuímos uma espécie de "velcro" para "grudar" experiências e emoções negativas e um tipo de "teflon" para "não grudar" as positivas. Por outro lado, hoje sabemos que nosso cérebro apresenta uma característica bastante estudada pela neurociência, a "plasticidade cerebral", ou seja, a possibilidade de mudar essa configuração cerebral, estruturalmente constituída com base no viés negativo, e nos transformarmos em pessoas capazes de focar os aspectos positivos da nossa vida. Uma das formas de mudarmos o viés negativo e experimentarmos mais emoções positivas do que negativas é a prática da gratidão, pois ela nos possibilita mudar o olhar para os elementos positivos da nossa experiência. Assim, é necessário um esforço consciente na valorização das emoções positivas em detrimento das negativas. 
- Engajamento: realizar atividades desafiadoras, de acordo com as habilidades individuais. Embora estejamos limitados quanto às nossas possibilidades em função do distanciamento e/ou isolamento social, ainda assim é factível encontrarmos atividades que nos motivem e nos desafiem, sejam elas relacionadas ao trabalho ou a algum hobbie. Que tal aprender algo novo, que sempre desejou e nunca encontrou tempo para colocar em prática? São várias as possibilidades, tais como aprender a cozinhar, a tocar um instrumento musical, a falar uma nova língua etc. $\mathrm{O}$ importante é que você se sinta realmente engajado em alguma atividade.

- Relacionamentos: manter relacionamentos de qualidade com pessoas significativas. Um dos principais aspectos sobre relacionamentos é considerar que a vida é um eco: se você não está gostando do som que está recebendo, observe aquilo que está emitindo. Em tempos de pandemia, torna-se ainda mais necessário colocar em prática a empatia, a generosidade, a gentileza, a amorosidade para que possamos experimentar relações positivas e de qualidade. Na impossibilidade de encontros presenciais, podemos lançar mão dos meios digitais para mantermos contato com as pessoas que nos são caras. É claro que nenhum encontro virtual substitui o real, mas é uma maneira de combatermos a solidão nesses tempos difíceis.

- Sentido: criar e fazer a vida ter sentido, de modo que ela valha a pena ser vivida. Não há um sentido único que dê conta de toda uma existência; pelo contrário, o sentido é constantemente construído e renovado ao longo da nossa vida. Especialmente em momentos de crise, como este que estamos vivendo, somos desafiados a encontrar um sentido para a nossa existência e nos conectarmos a ele, de modo que a vida não caia numa espécie de vazio existencial.

- Realizações: ter objetivos na vida, sejam pequenos ou grandes, e fazer esforços para alcançá-los. Trata-se também de valorizarmos o que somos e temos no aqui e agora e sermos gratos por isso. Valorize a pessoa que você já é: em vez de olhar para o que você não é (agora), tente focar nas suas qualidades, forças, virtudes e em tudo que já evoluiu até aqui. Além disso, comemore suas conquistas: aprenda a celebrar suas vitórias pessoais, sejam grandes ou pequenas.

Considero que não há gabarito para a vida que seja aplicado a qualquer pessoa, pois o mundo que alegra gregos, não agrada troianos. Então, a vida que vale a pena ser vivida só pode ser uma: a sua, essa mesma que você está vivendo desde que nasceu. É a vida que vale a pena 
por si, no instante em que é vivida. E isso ocorre quando nos ajustamos ao universo, ocupando o nosso lugar, desempenhando com excelência a atividade para a qual fomos talhados e buscando a finalidade que nos foi destinada como parte do todo. E como posso saber se estou fazendo aquilo que me cabe nesta existência? Estando no lugar em que sou feliz e vivo uma vida boa. Às vezes, penso que ser feliz é algo que está na simplicidade, sem excessos ou adereços.

Para Viktor Frankl, psiquiatra austríaco que esteve por quatro anos nos campos de concentração nazistas durante a Segunda Guerra, tudo pode ser tirado de uma pessoa, exceto a liberdade de escolher sua atitude em qualquer circunstância da vida. Com isso, ele nos diz que temos a possibilidade de decidir e não apenas sermos reféns do nosso destino. Nessa perspectiva, recomenda: quando a situação for boa, desfrute-a; quando a situação for ruim, transforme-a; quando a situação não puder ser transformada, transforme-se (FRANKL, 2017). Isso nos traz mais alguns elementos para pensarmos sobre a importância de viver com plenitude os momentos bons e de nos transformarmos com as situações ruins; ou seja, sempre há possibilidade de aprender e crescer com o sofrimento que a vida nos apresenta. É claro que ninguém deseja o sofrimento, mas é importante entender que faz parte da existência humana e que, mais dia menos dia, ele baterá à nossa porta.

Ainda pensando em sentido, ressalto que as coisas não têm sentido em si; somos nós que atribuímos sentido a tudo que experimentamos, e essa é uma tarefa absolutamente pessoal e indelegável. Elisabeth Lukas nos apresenta outro caminho possível para encontrarmos sentido em nossas vidas: o equilíbrio entre possibilidades e necessidades. Quanto maior é o nível e a quantidade de possibilidades, menos se dá valor a elas. Por outro lado, quando as possibilidades são escassas, sua valoração é feita de maneira mais ávida (LUKAS, 1992).

Estudos recentes (BOYCE et al., 2017; NATALI et al., 2018) têm evidenciado que há uma correlação positiva entre dinheiro e felicidade até certo ponto (que seria o necessário para uma vida digna e confortável). Após esse ponto, ter mais dinheiro não significa necessariamente ser mais feliz, em grande parte porque as possibilidades se tornam quase infinitas. Ou seja, a falta de dinheiro contribui para a infelicidade, quando as pessoas não têm o mínimo para garantir uma vida digna. Entretanto, ter dinheiro em abundância não garante a felicidade. Se, por um lado, a falta de recursos básicos prejudica um nível mínimo de felicidade, seu aumento não produz maior felicidade. Tal-Ben Shahar, professor da Universidade de Harvard, observa a relação entre riqueza material e felicidade, e questiona por que tantas pessoas correm o risco 
de falir emocionalmente, a despeito do nível sem precedentes de riqueza material. Assim, esclarece a ausência de relação estreita entre dinheiro e felicidade (SHAHAR, 2018).

Ainda sobre a questão das possibilidades e necessidades, penso que a busca pela felicidade está ligada à equalização das expectativas com a realidade. Quando as expectativas são muito elevadas, tem-se uma tendência à frustração quando elas não são atingidas; por outro lado, quando temos objetivos e metas mais realistas, tendemos a nos sentir satisfeitos e realizados quando conseguimos alcançá-los. A frustração costuma ter a medida do desejo que não se realizou ou da nossa incapacidade de aceitar o real. O ideal é que as nossas expectativas sejam menos hiperbólicas e inatingíveis e nossos desejos sejam mais factíveis e "humanos" como ser mais amoroso, empático, generoso — até consigo mesmo!

Outro aspecto importante, evidenciado nos estudos de Sonja Lyubomirsky, pesquisadora e professora de psicologia da Universidade da Califórnia (EUA), é que a felicidade é 50\% determinada por fatores genéticos; ou seja, intervimos muito pouco nesses fatores; $10 \%$ determinada pelas circunstâncias, ou pelo meio externo, também difíceis de serem controlados, e $40 \%$ determinada pelo estado interno da mente - nisso podemos intervir com mais possibilidades de êxito (LYUBOMIRSKY, 2008). Ora, se é difícil mudar características geneticamente determinadas, tampouco intervir nas circunstâncias externas; resta-nos trabalhar na maneira como encaramos o mundo à nossa volta e seguir o que foi citado anteriormente por Frankl: "Transforme-se".

Nessa perspectiva, poderíamos pensar numa fórmula em que a felicidade seria resultante da nossa carga genética + circunstâncias da vida + estado interno da mente, conforme demonstrado a seguir:

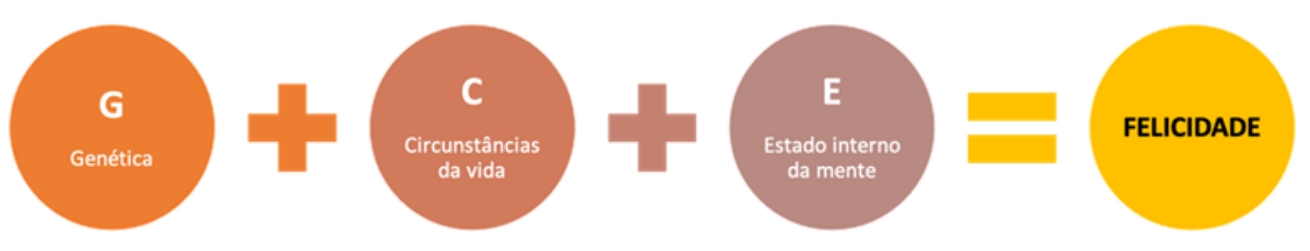

Figura 3: Fórmula da felicidade.

Vivemos, atualmente, numa espécie de "ditadura da felicidade"; ser feliz virou quase uma obrigação - conforme divulgado, frequentemente, na mídia e redes sociais. Esta seria uma compreensão muito rasa de felicidade. No atual contexto de pandemia, acredito que, se a pessoa é feliz o tempo todo, é porque não está entendendo nada! 
Curiosamente, quando nos libertamos da "obrigação" de ser feliz de maneira constante e ininterrupta - quase eufórica —, a felicidade chega, sem avisar. Conforme mencionado anteriormente, com frequência, ela está na simplicidade do nosso cotidiano.

Das várias definições de felicidade, a que mais aprecio deriva da ideia de Santo Agostinho (2004, p. 29): “o querer e o possuir serão um só e mesmo ato”, ou seja, felicidade é seguir desejando aquilo que já possuímos. Isso implica em aceitar a vida com sua beleza e complexidade e amar o que temos aqui e agora, em vez de desejar incessantemente aquilo que não possuímos. A felicidade pode, então, ser entendida como a aceitação espontânea da vida como ela é - e não como gostaríamos que fosse.

Melhorar os níveis de felicidade não é o mesmo que diminuir a infelicidade. Vejamos o exemplo dos antidepressivos, classe das drogas que passaram a ser utilizadas em larga escala a partir da década de 1990, conhecidas como "pílulas da felicidade". Atuam exclusivamente na melhora de quadros depressivos. Mas quem não apresenta algum transtorno mental não ficará mais feliz ao usar esse tipo de medicação. Combater o sofrimento não garante a felicidade, que depende de assumir uma postura diferente de encarar a vida, mais esperançosa e otimista.

Um dos maiores aprendizados que a pandemia nos trouxe foi a questão de viver no presente, ou seja, desfrutar e saborear o que está acontecendo enquanto está acontecendo. Isso implica abrir mão da nostalgia dos momentos vividos e da projeção dos momentos a viver. Quando nos apressamos para estar em algum outro lugar, o resultado é nunca estarmos de fato onde estamos, o que constitui uma grande perda, pois acabamos sem desfrutar o momento presente. Para que isso seja possível, é necessário desenvolver a paciência, que implica compreender que tudo acontece a seu próprio tempo. Nesse sentido, é fundamental termos em mente a noção de transitoriedade, inerente à experiência humana. Ter essa ideia nos empodera para vivermos tanto bons quanto maus momentos. Se a situação for ruim, tenha clareza de que vai passar, não há mal nem bem que dure para sempre. E, se a situação for feliz e especial, desfrute-a, pois também vai passar.

Viver feliz é uma arte, não uma ciência exata, pois depende de sensibilidade, coragem, autoconhecimento, oportunidade, disponibilidade, timing. Ser feliz é uma aventura, uma busca permanente de encontro com aquilo que é essencial na sua vida. Lembro outra vez que cabe a você (e a mais ninguém) a decisão de viver uma vida mais feliz e autêntica. Embora pareça contraditório falar em felicidade em tempos tão difíceis como estes que estamos vivendo, é possível encontrá-la na simplicidade do nosso dia a dia, nos “pequenos grandes" momentos da nossa vida cotidiana, pois, conforme foi apresentado, a felicidade tem uma relação estreita com 
nosso estado interno da mente e com a forma como encaramos o mundo. Não se trata de brincar de "jogo do contente" de forma ingênua e abobada, mas sim valorizarmos as dádivas que a vida nos oferece.

\title{
CONSIDERAÇÕES FINAIS
}

Voltemos à questão inicial, mote do presente texto: é possível viver saudável e feliz em tempos de pandemia? Neste ponto, imagino que cada qual possui uma resposta, ainda que parcial, para tal questionamento. Não tenho a pretensão — na verdade não a tive desde o início —, de oferecer uma resposta definitiva, até porque não acredito em "verdades absolutas".

Perdoe-me se lhe deixei com mais dúvidas do que respostas, com mais pontos de interrogação do que de exclamação. $\mathrm{Na}$ verdade, esse era o meu verdadeiro intuito. Minha intenção nunca foi lhe apresentar uma "receita ou chave da saúde e da felicidade", tampouco fazer da minha procura a sua. O que eu quis, de fato, foi oportunizar reflexões para que você - e mais ninguém - encontre o caminho que é seu: único, especial, irrepetível e personalíssimo nessa incessante construção da saúde e da felicidade.

Que possamos, dia após dia, encontrar novas e/ou diferentes possibilidades de vivermos com saúde e felicidade, mesmo em tempos tão adversos como estes que estamos enfrentando. E que tenhamos sempre em mente que não há crise que se eternize em sua agudez, ou seja, cedo ou tarde tudo isto vai passar, e nós, provavelmente, sairemos desta tempestade mais sábios e resilientes.

E, para finalizar, cito Lya Luft (2009, p. 36), que nos lembra:

\begin{abstract}
A vida não está aí para ser suportada ou vivida, mas elaborada. Eventualmente reprogramada. Conscientemente executada. Existir é poder refinar nossa consciência de que somos demais preciosos para nos desperdiçarmos buscando ser quem não somos, não podemos, nem queremos ser. Não é preciso realizar nada de espetacular. Mas o mínimo que seja o máximo que a gente conseguiu fazer consigo mesmo.
\end{abstract}

\section{REFERÊNCIAS}

AGOSTINHO, Santo. O livre-arbítrio. São Paulo: Paulus, 2004. 300p. (Coleção Patrística, n. 8).

BOYCE, Christopher J. et al. Money may buy happiness, but often so little that it doesn't matter. Psychological Science, v. 28, n. 4, p. 544-46, 2017. 
FRANKL, Viktor. Em busca de sentido: um psicólogo no campo de concentração. Petrópolis: Vozes, 2017. 140p.

KAFFENBERGER, T. et al. Negative bias of processing ambiguously cued emotional stimuli. Neuroreport, v. 21, n. 9, p. 601-5, 2010.

LUFT L. Perdas e ganhos. Rio de Janeiro: Record, 2009. 140p.

LUKAS, Elisabeth. Assistência logoterapêutica. Petrópolis: Vozes/Sinodal, 1992. 232p.

LYUBOMIRSKY, Sonja. A ciência da felicidade: como atingir a felicidade real e duradoura. Rio de Janeiro: Elsevier, 2008. 324p.

MASLOW, Abraham H. Introdução à psicologia do ser. Rio de Janeiro: Eldorado, 1978. 252p.

NATALI, Luisa et al. Does money buy happiness? SSM Population Health, v. 4, p. 225-35, 2018.

ORAGANIZÇÃO PAN-AMERICANA DE SAÚDE (OPAS). [202-]. Histórico da pandemia de Covid-19. Acesso em: 31 maio 2021. Disponível em:

https://www.paho.org/pt/covid19/historico-da-pandemia-covid-19

SELIGMAN, Martin E. P. Felicidade autêntica: use a psicologia positiva para alcançar todo o seu potencial. Rio de Janeiro: Objetiva, 2019. 336p.

SHAHAR, Tal-Ben. Seja mais feliz: aprenda a ver alegria nas pequenas coisas para uma satisfação permanente. São Paulo: Planeta do Brasil, 2018. 224p. 